\title{
$\mathrm{PH} 104_{\text {debate }}$
}

a debate Patrimonio cultural y cambio climático

| coordina Alejandro García Hermida

\section{Paisajes rurales y energías renovables. Un patrimonio cultural bajo amenaza}

Anna Martínez Durán, Montserrat Villaverde Rey | Escola Arquitectura La Salle, Universitat Ramon Llull

URL de la contribución <www.iaph.es/revistaph/index.php/revistaph/article/view/4986>

Una de las consecuencias del cambio climático es el paso del sistema de producción de energías fósiles a energías renovables. Con este escrito se quiere poner de manifiesto la destrucción del patrimonio tradicional que va a suponer la implantación de macroproyectos de instalaciones eólicas y fotovoltaicas. Su aterrizaje en las zonas rurales más frágiles de nuestro país representará en muchos casos la desaparición de unos paisajes de gran belleza y dignidad, que residen en la memoria del pueblo y construyen su identidad (Nogué i Font 2010). También de una forma de vida y una cultura heredadas, y del sistema económico y social que los mantiene vivos. Proyectos emplazados lejos de los centros de consumo, que se instalan en zonas deprimidas por su bajo valor, por la poca resistencia social que encuentran, en definitiva, porque la producción es más fácil y rentable (Saladié 2018).

Nuestro planteamiento parte de poner en valor estos territorios ocultos, construidos a lo largo de siglos, por y a escala de hombres y mujeres que aprovecharon los recursos del lugar para transformar lo inhóspito en un paraíso. Lugares que siguen siendo ricos en biodiversidad: flora, fauna, suelos, agua... porque el hombre estableció, en su asentamiento, un pacto de equilibrio con la naturaleza.

El caso de estudio se desarrolla en los alrededores de la población de El Perelló (Baix Ebre, Tarragona), situado en un alto $(150 \mathrm{~m})$, entre las sierras del Cardó y del Boix y el mar, en una zona de geología calcárea cruzada por barrancos, con manantiales de aguas claras y cuevas, que han sido refugio desde la época neolítica (cuevas de Cabra i Feixet, del Duc, de la Masa). Restos arqueológicos lo sitúan en el trazado de la Vía Augusta (Izquierdo i Tugas 1989). Con una carta fundacional de
1294, fue ciudad amurallada, y en ella se construyó un hospital real (1313) (Boyer i Gil y Pallarès i Lleó 1978). Lugar de tránsito y de defensa, de mezcla de gente, en la época moderna estuvo en primera línea de la batalla de l'Ebre, fue reconstruida por la Dirección General de Regiones Devastadas y Reparaciones, y las curvas de la nacional N-340 aún están en el recuerdo de nuestros padres y abuelos en sus primeros periplos por la costa mediterránea.

Los habitantes de El Perelló transforman desde principios del s. XVIII un territorio árido y pedregoso en campo de cultivo. Con el pago de los censals redimen la propiedad y ganan su libertad: "durant el día treballaven a jornal, i per la nit arrabassaven garrigues, plantaven figueres i oliveres, feien marges, carboneres, etc. En definitiva, les terres de secà del nostre terme han estat regades per la suor de la que podríem dir que ha fet història" (Boyer i Gil y Pallarès i Lleó 1978). Casi 300 años después, bajo el viento de mistral, se siguen cultivando almendros, olivos, higueras y algarrobos, se sigue cazando, y se sigue habitando en casetas diseminadas, manteniendo el carácter familiar e independiente original: "tal com és la tradició, una casa de faena, de festa o de reunió" (Generalitat de Catalunya 2014).

La máxima frente al Mediterráneo de Le Corbusier de "mantener el tesoro de la escala" y la consecución de la libertad individual que dio lugar a la construcción de esta obra comunal: "va ser la gent la que va canviar la fesomia del paisatge" (Aragonés Gisbert et ál. 2010) son los dos ejes que están en el origen de este paisaje, y que se ven ahora amenazados.

Un patrimonio cultural escrito con minúsculas, una arquitectura tradicional sin nombres propios: "construida pels 

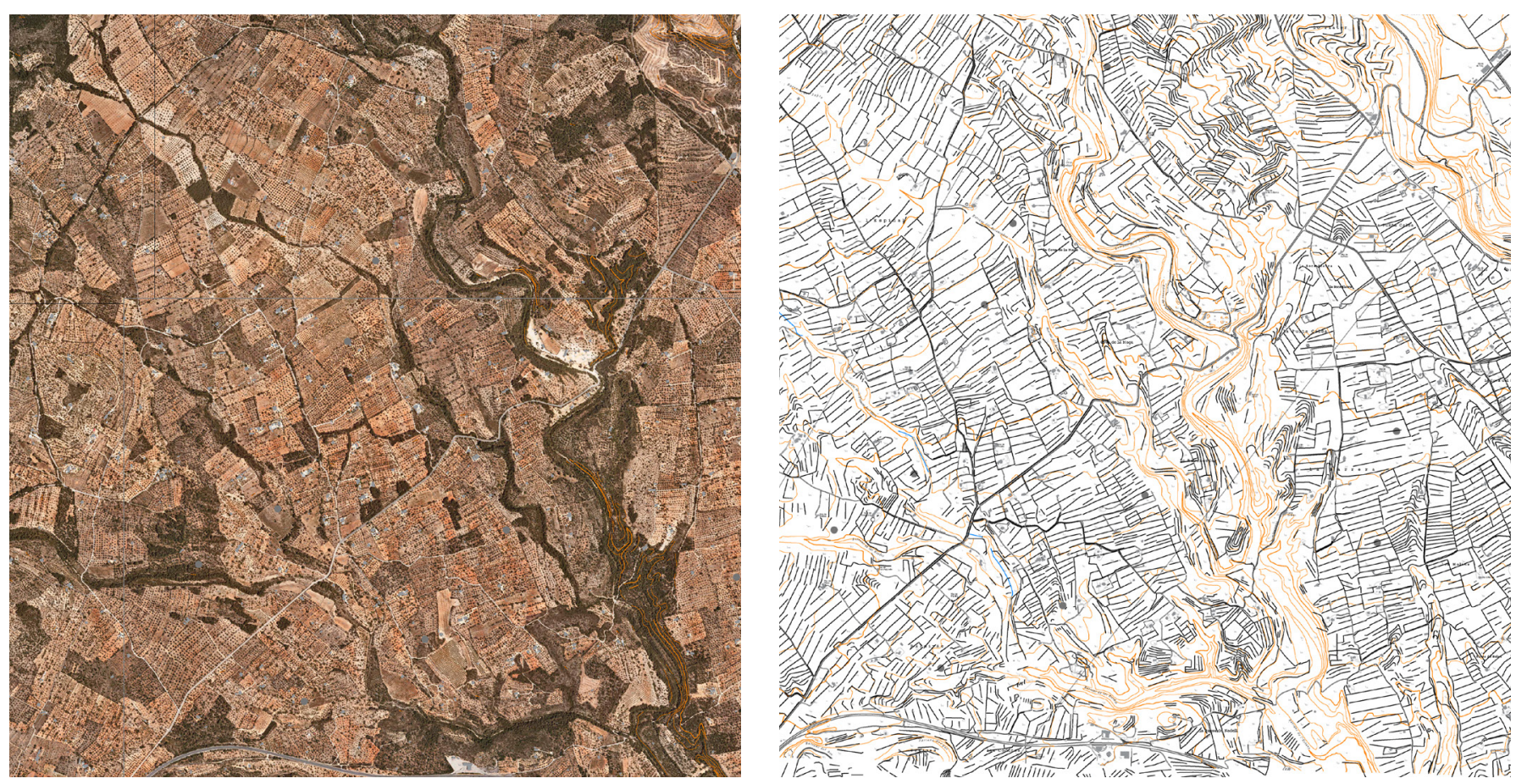

Visión aérea del paisaje rural: mosaico agrario, geometrías construidas, muros de piedra seca. Ortofoto y dibujo propio sobre base del ICGC | fuente Institut Cartògràfic i Geològic de Catalunya

habitants d'un territori a partir d'uns models compartits, creats de manera colectiva a través de les generacions" (Van Geert y Estrada Bonell 2018), fundamento de una gran cultura, la mediterránea.

El proyecto en curso propone revelar la existencia de este patrimonio cultural, material e inmaterial: grafiarlo, fotografiarlo (Cortellaro 2007), reconocer historias, costumbres y actividades para dar continuidad a la reflexión actual sobre el conflicto entre el paisaje y las energías renovables (ALIENTE 2021).

Características del patrimonio cultural de este lugar, y razones por las que deberíamos conservarlo, son:

> Una división parcelaria que conforma un atractivo "mosaico agrario" (Observatori del Paisatge 2010), con parcelas de pequeño tamaño (0,5-3 ha), lo tros (el trozo), que dan la medida del terreno abarcable por el trabajo de cada persona, para la subsistencia familiar.
> La antigua Nacional 340, asimilada popularmente a la Vía Augusta (Perea Paños 2016), estructura el territorio, con estrechos caminos de acceso a lado y lado, entre muros de piedra, que siguen la topografía (a pendiente y a nivel) y en continuidad cuando son paso de ganadería, los "pasos de ligallos".

$>$ No hay límites en el paisaje al paso de personas ni de animales, tampoco a las visuales que se extienden a lo lejos, por debajo de las copas de olivos y algarrobos.

> Los muros de piedra seca (en la Lista de Patrimonio Cultural Inmaterial de Unesco desde 2018) organizan el terreno en bancales horizontales para retener la escasa lluvia, definen los límites de la propiedad, son almacenes de piedra y refugio de cazadores. Sus trazados son pura geometría: líneas rectas y quebradas, curvas sinuosas.

> Las construcciones son menores en tamaño, no en servicio ni en calidad arquitectónica: con un alto nivel de 

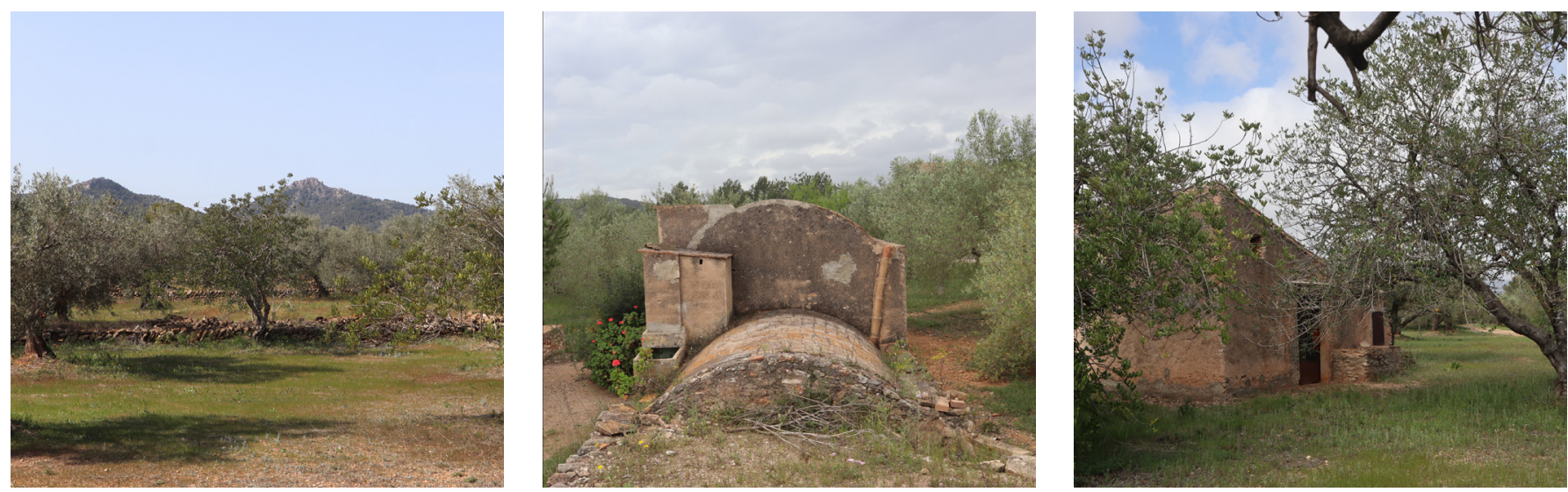

Elementos naturales y construidos de este paisaje mediterráneo: el Tossal de Montagut, cisterna de bóveda cerámica y caseta del tros | fotos Anna Martínez Durán

abstracción, son únicas de este lugar. Se esparcen por el territorio: masets y casetes del tros (Ferrer 2006), cisternes y valonas, eres, corrals y pallisses. Sencillos elementos que forman conjuntos orgánicos, de relaciones cercanas y geometrías compartidas. En estas construcciones domésticas se usan la piedra seca, la mampostería de barro, los techos de vigas de madera y las bóvedas de rasilla cerámica (García Lisón y Zaragozá Catalán 1983).

> Algarrobos y olivos centenarios, plantados con regularidad y orden por mentes sabias, producen un aceite compensado entre especies y sabores, sus raïls (raíces) expuestas en un terreno seco y ventoso.

> Las montañas de Cardó y del Boix presiden el llano, el monte más cercano es el Tossal de Montagut (394 m), paso de cátaros entre el Ebro y el Mediterráneo. Estos montes pedregosos son referencia de paisaje y memoria del lugar. La pintura moderna nace con la reflexión plástica de Paul Cézanne frente a Sainte Victoire porque en cada montaña reside una carga simbólica que nos ancla al territorio. Son lugar sagrado y la casa a la cual regresar, mantenerlas limpias es nuestra obligación.

Este territorio entre El Perelló y l'Ametlla de Mar sigue vivo, con tráfico de coches, tractores, bicicletas, caminantes y gentes que producen aceite y miel, recogen almendras, algarrobas, y residen en casetas que, en pleno siglo XXI, siguen siendo autosuficientes en el consumo de agua y energía. Un lugar con unos niveles muy altos de silencio y limpieza del aire, también lumínica, que en estos momentos está siendo amenazado por proyectos de gran envergadura, eólicos y fotovoltaicos, promovidos por grandes empresas ajenas al territorio.

Uno de ellos prevé la instalación de 10 aerogeneradores a ambos lados de la antigua $\mathrm{N}-340$, de 180 metros, 3,6 $\mathrm{mW}$ y $115,5 \mathrm{~dB}$ cada uno. Los más de $7 \mathrm{~km}$ de caminos abiertos para acceder unas alas de $64 \mathrm{~m}$, las plataformas de montaje, de 1 ha cada una, las cimentaciones y las zanjas, la central eléctrica y el nuevo tramo de evacuación aérea, van a convertir este paraje agrario, patrimonial, a escala humana, en un polígono industrial, ruidoso, a medida de las máquinas, y desierto, vacío de gente. En definitiva, estamos frente a la destrucción de un lugar histórico, patrimonial, y de su imaginario colectivo, de su identidad.

Como este, tantos otros lugares en nuestro país han llegado hasta nosotros en calma, en estado latente (Sala i Martí 2016). Paisajes patrimoniales que ahora podrían verse beneficiados por la inversión pública dando continuidad a esta obra comunitaria pero que, de ceder a la amenaza de estos macroproyectos en manos de las grandes empresas, verán su futuro humano y económico truncado, y su paisaje, su identidad, destrozados, sin vuelta atrás. 


\section{BIBLIOGRAFÍA}

- ALIENTE [Alianza Energía y Territorio] (2021) Por la conservación de la biodiversidad, el paisaje, y por el desarrollo de un modelo energético distribuido y justo. Manifiesto. Disponible en: https://aliente.org/manifiesto [Consulta: 15/09/2021]

- Aragonés Gisbert, J., Estorach Fatsini, M., Ferré Castell, C., López Daufí, A., Olivas Rodríguez, J. y Ollé Garcia, S. (2010) La pedra en sec a les comarques del Baix Ebre i del Montsià. Benicarló: Onada Edicions

- Boyer i Gil, A. y Pallarès i Lleó, A.(1978) Història d'El Perelló, vol. 1. [S.L : S.n]

- Cortellaro, S. (2007) Morna, Atzaró. La construcción del territorio de Eivissa. Palma de Mallorca: COAIB

- Ferrer, A. (2006) Les casetes del tros. Una arquitectura vernacular. Memòria del Perelló, n. ${ }^{0} 1$

- García Lisón, M. y Zaragozá Catalán, A. (il.) (1983) Monográfico La vivienda temporera en las comarcas del Maestrat i les Terres de l'Ebre. Centro de Estudios del Maestrazgo, año I, n. ${ }^{\circ} 1$ Disponible en: https://pedraseca. gva.es/documents/168838666/168851333/Garc\%C3\%ADaZaragoz\%C3\%A1\%20Pallisses+\%26+casetes+de+volta. pdf/82a1c11b-7e45-477b-ba91-3be63fb0bde1 [Consulta: 14/07/2021]

- Generalitat de Catalunya (2014) Pla Director Urbanístic de les construccions agrícoles tradicionals de les Terres de l'Ebre. Disponible en: https://territori.gencat.cat/ca/inici [Consulta 09/07/2021]

- Izquierdo i Tugas, P. (1989) Un tram de la Via Augusta al Perelló i una proposta d'urbanització. Butlletí Arqueològic. Reial Societat Arqueològica Tarraconense, n. ${ }^{\circ}$ 10-11, pp. 169-191. Disponible en: https://raco.cat/index.php/ButlletiArq/ article/view/315454 [Consulta: 18/07/2021]

- Nogué i Font, J. (2010) Paisatge, territori i societat civil. Valencia: Tres i Quatre

- Observatori del Paisatge (2010) Catàleg de Paisatge de les Terres de l'Ebre. Disponible en: http://www.catpaisatge.net/cat/ catalegs_presentats_E.php [Consulta: 09/07/2021]

- Observatori del Paisatge (2007) Paisatges de la pedra seca. Disponible en: http://www.catpaisatge.net/dossiers/pedra seca/cat/index.php [Consulta: 09/07/2021]

- Perea Paños, L. (2016) Entre Pinón i Tria Capita: Estudi del pas de la Via Augusta i d'una possible mutatio al municipi del Perelló. Universitat Autònoma Barcelona (TFG). Disponible en: https://docplayer.es/97839700-Entre-pinon-i-tria-capitaestudi-del-pas-de-la-via-augusta-i-d-una-possible-mutatio-almunicipi-del-perello.html [Consulta: 09/07/2021]
- Saladié, S. (2018) Conflicte entre el paisatge i l'energia eòlica. El cas de les comarques meridionals de Catalunya. Lleida: Pagès Editors

- Sala I Martí, P. (2016) Paisatges latents. Aportacions de l'Observatori del Paisatge de Catalunya. Presentación en el Simposio Sòl No Urbanitzable, en Olot, 14 de octubre de 2016, Colegio de Arquitectos de la Demarcación de Girona. Disponible en: https://es.slideshare.net/psala/paisatgeslatents-aportacions-de-lobservatori-del-paisatge-de-catalunya [Consulta: 09/07/2021]

- Van Geert, F. y Estrada Bonell, F. (2018) Construint el territori: arquitectura tradicional i paisatge a Catalunya. Departament de Cultura de la Generalitat de Catalunya. Disponible en: https://cultura.gencat.cat/web/.content/cultura popular/05 documents_i_recursos/04_exposicions_itinerants/Construint_ territori/SD_Construint_territori.pdf [Consulta: 15/09/2021] 